\title{
Análisis teórico de la transferencia de conocimientos universidad-empresa mediante la colaboración*
}

\author{
Rodolfo García Galván**
}

\section{RESUMEN}

Para lograr la competitividad de cualquier economía de nuestros días es necesario el conocimiento científico y tecnológico producido en las universidades y en las empresas. Sin embargo, por sus características implícitas, las empresas no siempre están dispuestas a hacer inversiones relevantes en investigación; en tal situación, las universidades son las que generan la mayor parte del conocimiento científico y tecnológico que a la vez es de gran utilidad para las empresas. Entonces, en un proceso que parece ser complementario, cada vez es más notorio el fenómeno de la colaboración empresa-universidad. Pero este proceso no está exento de problemas de definición de los mejores mecanismos para la interacción.

Núero de clasificación: JEL: D21, D23, D83, O32

Palabras clave: conocimiento, competitividad, complementariedad, colaboración, mecanismos de interacción.

\begin{abstract}
The scientific and technological knowledge produced in the universities and in the firms is necessary to achieve the competitiveness of any economy of our days. Nevertheless, for its implicit characteristics, the firms not always are ready to do relevant investments in research; in such a situation, the universities are those that generate most of the scientific and technological knowledge that simultaneously is of great usefulness for the firms. Then, in a process that seems to be complementary, every time the phenomenon of the collaboration is more well-known firm-university. But this process, it is not exempt from problems of definition of the best mechanisms for the interaction.
\end{abstract}

Clasification number: JEL: D21, D23, D83, O32

Key words: knowledge, competitiveness, complementary, collaboration, mechanisms of interaction.

* Una versión preliminar de este trabajo fue presentada como ponencia en el V Congreso Internacional Innovación, Tecnología y Desarrollo Regional (nexo Universidad-Empresa y RIDIT), San José, Costa Rica, 8-10 de octubre de 2008. Se agradecen los valiosos comentarios y sugerencias de los dictaminadores anónimos que sirvieron para mejorar la versión final del presente artículo.

** Estudiante del doctorado en Ciencias Económicas de la Universidad Autónoma Metropolitana y profesor de la Facultad de Ciencias Políticas y Sociales de la Universidad Autónoma del Estado de México. 


\section{INTRODUCCIÓN}

La frase "economía basada en el conocimiento" describe el nuevo ambiente económico en el cual la generación y la gestión de conocimiento desempeñan un papel predominante en la creación de la riqueza. Asimismo, el siglo XXI ha sido etiquetado como el "siglo del conocimiento", por tanto, la habilidad para crear, acceder y usar el conocimiento se ha convertido en una determinante fundamental de la competitividad global de empresas y economías (Burrone y Singh, 2004, p. 2). En estos escenarios la colaboración científica y tecnológica ${ }^{1}$ es de gran importancia.

Dado lo anterior, por ejemplo, en Estados Unidos, mucho del conocimiento avanzado está contenido en la investigación de las universidades, y en ese sentido, un componente central de la construcción de la economía del conocimiento ha sido la integración de la investigación universitaria al proceso de la propiedad intelectual. Además, la agenda de la competitividad fija su atención en las universidades como motores de la innovación y del crecimiento económico potencial; a esto, desde la perspectiva de algunos autores (Rhoades, 1996 y 2004; Slaughter y Leslie, 1997; Welsh, 2008, p. 1857), se le puede llamar simple y llanamente "capitalismo académico". Desde luego que esa idea se sustenta en el hecho de que los sectores industriales más competitivos y con mayor crecimiento basan sus ventajas en una fuerte vinculación con la ciencia y la tecnología que proviene de las mismas universidades (Pavitt, 1984; Blumenthal et al., 1986; Arora y Gambardella, 1990; Cockburn y Henderson, 1998).

Tampoco es desconocido que en los países más desarrollados se impulsa de manera decisiva el financiamiento público y privado de las nuevas líneas de investigación, ${ }^{2}$ como una estrategia para ampliar las capacidades y las habilida-

\footnotetext{
${ }^{1}$ En el documento las categorías de colaboración y cooperación se asumen como sinónimos. También la investigación científica y tecnológica pueden utilizarse como conceptos sustitutos de ciencia y tecnología. Además, es importante aclarar desde ahora la diferencia entre mercados competitivos y competitividad de las empresas. En los primeros, se aplican los supuestos neoclásicos de la competencia perfecta, en tanto que la competitividad empresarial se refiere a la adquisición de habilidades y capacidades para enfrentar la competencia de mejor manera.

${ }^{2}$ Por ejemplo, durante el gobierno de Clinton se difundió en la prensa que se había tomado la decisión estratégica de crear un fondo especial del presupuesto federal para impulsar y consolidar un campo emergente de investigación. Se trataba de aportar mayores recursos para el desarrollo de la nanotecnología, y más genéricamente, de las ciencias de los materiales. Ahora mismo, un decreto firmado por el gobierno de Obama para asignar fondos federales a la investigación con células madre, dio nuevo impulso a un campo del conocimiento en el que tal experimentación había sido prohibida por el gobierno anterior.
} 
des de las empresas para competir en un entorno mundial. No es un secreto que estos países son los que más invierten en ciencia y tecnología como proporción del PIB. A esta lista se han agregado países de reciente industrialización, como Corea del Sur y Taiwán, donde la vinculación de la industria con los centros tecnológicos y las universidades ha sido decisiva (Merritt, 2007). Adicionalmente, algunos países que conforman el grupo de las denominadas economías emergentes, como Brasil, China e India, que en el futuro serán grandes potencias económicas (Jaliffe-Rahme, 2007), están basando, en parte, su presencia mundial en las mayores inversiones en la investigación científica y tecnológica. Así pues, la India es ejemplo mundial en el desarrollo de software, en tanto que Brasil fue precursor en el desarrollo de los biocombustibles.

Queda claro que la cooperación tecnológica (y científica) no se limita a las alianzas suscritas entre las empresas, y cualquier enfoque teórico que pretenda generalizarse sin abordar el asunto de la vinculación empresa-universidad nace debilitado, pues la colaboración entre las instituciones del conocimiento y las dedicadas a producir y generar riqueza se ha incrementado de manera muy clara en las últimas décadas. De hecho, la innovación se origina cada vez más fuera de la empresa individual, procedente de otras esferas institucionales u organizacionales como la universidad, donde el centro de atención está en la ciencia y la tecnología. Por tanto, a medida que la innovación se desarrolla afuera de una simple organización, las relaciones laterales por medio de las fronteras se tornan más importantes (Etzkowitz, 2002, p. 1). Debido a ese fenómeno, los estudios al respecto apenas se inician con preguntas sin respuestas.

De hecho, David (1994, p. 66, en Welsh et al., 2008, p. 1863) señala que la ciencia universitaria es a la economía del siglo XXI lo que el sector de las máquinas-herramientas fue a las economías del siglo XIX y de principios del XX. Por eso se requieren mecanismos inteligentes y creativos para fortalecer las interacciones de las universidades con el sector privado.

Por otro lado, en el mundo económico las instituciones que coordinan la actividad pueden ir desde el mercado (en el que el precio juega un papel central) hasta las empresas convencionales (donde se centralizan las decisiones). Pero entre ambas posiciones extremas existen mecanismos de coordinación híbrida, es decir, que se ubicarían entre el mercado y la empresa; uno de tales mecanismos lo constituyen los acuerdos o alianzas colaborativas o bien cooperativas entre distintas organizaciones (Williamson, 1975 y 1985; García et al., 2004). Por las funciones empresariales que están adquiriendo las universidades, éstas podrían ubicarse como organizaciones intermedias en la coordinación de la actividad económica. 
Al respecto, en este trabajo se asume que cuando las empresas y las universidades establecen acuerdos de colaboración formal o tácita es porque buscan la complementariedad de los activos físicos e intangibles, y debido a que por medio de la cooperación logran reducir costos de producción y de transacción de los proyectos de investigación, incluyendo los riesgos compartidos y los potenciales derramamientos del conocimiento o la inapropiabilidad del mismo. También, por medio de la colaboración, ambas organizaciones adquieren mayores capacidades y habilidades en el desarrollo de la investigación científica y tecnológica.

El propósito de las siguientes páginas es delimitar y explicar teóricamente los rasgos más sobresalientes de la colaboración universidad-empresa, a partir de los fundamentos de la teoría de las externalidades y, sobre todo, de la nueva economía institucional, con el fin de hacer una valoración de los alcances y las limitaciones de este mecanismo de coordinación. Debe señalarse que no ha habido esfuerzos significativos en cuanto a la construcción de una teoría de la colaboración empresa-universidad; a lo más que se ha llegado es a esfuerzos aislados en los que las universidades desempeñan un papel secundario en el desempeño económico y a veces esos esfuerzos parecen excluyentes o sustitutos (las teorías de los sistemas de innovación y de la triple hélice son excepciones notorias); por tanto, el presente artículo pretende aportar elementos para profundizar en una teoría económica de la cooperación entre dos agentes que parecen distantes y que aclare bien la utilidad del conocimiento en las actividades económicas.

El documento se compone de los siguientes apartados: en primer lugar se abordan los fundamentos de la teoría de las externalidades-spillovers y de la nueva economía institucional (NEI). En segundo lugar se analiza la participación de las universidades en la actividad económica. El tercer apartado explica la colaboración empresa-universidad a partir de las herramientas teóricas de la NEI. En cuarto lugar se presentan los problemas teóricos y las oportunidades de investigación futura respecto a la colaboración empresa-universidad. Finalmente, se presentan las conclusiones.

Vayamos pues a lo que ha ocurrido y lo que está desarrollándose en los ámbitos empresarial y universitario respecto a las implicaciones económicas y organizacionales de la colaboración empresa-universidad en la producción, el intercambio (flujo) y la utilización del conocimiento. 


\section{DE LA TEORÍA DE LAS EXTERNALIDADES-SPILLOVERS A LA NUEVA ECONOMÍA INSTITUCIONAL}

Dos posturas teóricas han profundizado en la colaboración interempresarial e interinstitucional u organizacional. Por un lado, se encuentra el análisis neoclásico de las externalidades, más recientemente conocido como los spillovers del conocimiento. En esta perspectiva, las derramas se consideran una externalidad positiva y, por tanto, una falla del mercado competitivo, cuya solución tampoco puede ser competitiva, pues se antepone la colaboración o la predominancia de grandes empresas monopólicas u oligopólicas para el financiamiento de la investigación.

Por otro lado está la NEI, en la que son importantes categorías y variables que no se abordan en la bibliografía de las externalidades y de los spillovers, pero que tienen una riqueza explicativa suficiente para una comprensión más amplia de los acuerdos colaborativos empresa-universidad. Sin embargo, en este documento no existe la intención de confrontar ambas posturas teóricas, más bien se buscan los instrumentos analíticos necesarios para un entendimiento teórico a profundidad de la vinculación mencionada.

\section{Los supuestos básicos de la teoría de las externalidades-spillovers}

Uno de los trabajos que comenzaron a llamar la atención sobre las economías externas fue el de Alfred Marshall (1920, en Thompson et al., 2005, p. 450), que analiza los mayores beneficios obtenidos por las empresas aglomeradas en algún lugar, y que les permitía una especialización más alta junto con economías derivadas de un volumen de producción elevado y del crecimiento del conocimiento o del progreso de las técnicas industriales.

El propio Marshall ${ }^{3}$ (1920, pp. 265-266) señala que muchas de las economías encontradas en el ambiente industrial y derivadas de las habilidades especializadas o de la maquinaria, que normalmente están asociadas a los grandes establecimientos, no dependen del tamaño de las fábricas individuales. Algunas se derivan del volumen agregado de la producción; mientras que otras están vincu-

\footnotetext{
${ }^{3}$ El autor divide en dos clases las economías que son consecuencia del incremento en el nivel de producción. Primero, aquellas dependientes del desarrollo general de la industria (economías externas); y, segundo, aquellas dependientes de los recursos de los negocios individuales que se derivan de su organización y de la eficiencia de su gestión (economías internas).
} 
ladas al crecimiento del conocimiento y al progreso de las técnicas, ambas dependen principalmente del volumen agregado de la producción.

Otros trabajos seminales de la economía del conocimiento, sin abandonar la hipótesis de las externalidades, han mostrado la importancia de la inversión en ciencia y tecnología para alcanzar un mayor bienestar social y una mejora competitiva de las empresas; esto, debido a las economías de derrame que se generan y que alcanzan a los agentes que no tienen interés por invertir en tales actividades. En este contexto el trabajo de Richard Nelson (1959) analiza la cuestión de por qué las empresas (convencionales) nunca invertirán lo suficiente en investigación como una condición básica para la aparición a posteriori de las economías externas. ${ }^{4}$

De hecho, el problema de las mayores inversiones en ciencia y tecnología no es fácil de abordar porque las empresas asumen riesgos en nuevos negocios cuando saben que obtendrán una ganancia elevada, pero eso contrasta con las características del conocimiento o de la información como un bien tecnológico o innovador que difiere de los otros..$^{5}$ Las condiciones de inapropiabilidad absoluta, la elevada incertidumbre, la indivisibilidad, los retrasos y los altos costos son, de acuerdo con Keneth Arrow (1962) y Neil Kay (1988), las propiedades que impiden una inversión óptima de las empresas privadas en un entorno de economía competitiva. Por consiguiente, los mecanismos para buscar una mayor inversión están relacionados con organizaciones que escapan a la definición tradicional de la economía neoclásica.

El mismo Nelson (1959, pp. 144-145) ejemplifica dos casos en los que las empresas podrían invertir mayores recursos en las actividades innovadoras. Por

\footnotetext{
4 "[...] los adelantos significativos del conocimiento deben buscarse... en la investigación básica... Pero los esfuerzos... tenderán a generar considerables economías externas. No es probable que las oportunidades de ganancia privada tiendan... a atraer... la cantidad de recursos socialmente conveniente... Pocas empresas operan en un amplio campo de actividad económica que puedan beneficiarse directamente de todas las posibilidades tecnológicas creadas por los resultados de un esfuerzo exitoso de investigación básica... A [veces] el conocimiento nuevo tiene mayor valor como insumo... de otros proyectos... Por tanto, es muy probable que una empresa no pueda captar a través de los derechos de patente todo el valor económico creado en un proyecto de investigación básica que patrocine" (Nelson, 1959, pp. 143-144).

${ }^{5}$ En un artículo inédito, Arrow (1962, p. 151) señala que tres de las razones clásicas de la incapacidad de la competencia perfecta para alcanzar el óptimo en la asignación de recursos a la invención son: las indivisibilidades, la inapropiabilidad y la incertidumbre. Posteriormente, Kay (1988, pp. 282-283) señala que las cuatro características que tienen importancia central para las economías de la actividad de ID son las no-especificidades, los retrasos, la misma incertidumbre y los costos. La ID genera sinergias tecnológicas o economías de alcance, y gran parte de ésta no es productoespecífico y tampoco empresa-específica, lo que genera externalidades y problemas en los derechos de propiedad.
} 
un lado, una base tecnológica amplia de la empresa asegura que, cualquiera que sea la dirección de la investigación, los resultados tienden a ser valiosos para la empresa patrocinadora. De este modo, no es sólo el tamaño de las compañías lo que hace conveniente para ellas la realización de investigación básica, es más bien su amplia base tecnológica, el amplio conjunto de productos que fabrican o están dispuestas a fabricar si sus esfuerzos abren nuevas posibilidades. ${ }^{6}$ Además, una amplia base tecnológica no implica una posición de poder monopólico en alguno o en todos los mercados de productos, tampoco una posición monopólica en un mercado implica una amplia base tecnológica. En efecto, en una posición de mercado, una empresa lucrativa que opere en un ambiente competitivo raras veces encontrará rentable el financiamiento de un proyecto de investigación que no tienda a producir rápidamente algo patentable.

Por el otro lado, Nelson también menciona que muchas industrias han tratado de conciliar su necesidad de conocimientos nuevos con la falta de incentivos a las empresas privadas individuales para la producción de tales conocimientos, mediante la creación de cooperativas de investigación industrial. El impulso de la investigación puede convenir a todas las empresas, en la medida en que una industria descanse en un campo científico que probablemente logre escasa investigación aplicable a la tecnología de su ramo, aunque cada empresa preferirá que las demás absorban los costos financieros. Así pues, un laboratorio industrial de investigación cooperativa bien podría desarrollarse en estas condiciones, apoyado por la totalidad o por un gran número de las empresas de esa industria.

Desde luego que las razones para impulsar o ignorar los proyectos tecnológicos conjuntos entre las empresas, desde la perspectiva de la teoría de las externalidades, se relacionan con las propiedades del conocimiento científico y tecnológico. Aunque se debe estar consciente, en concordancia con Dominique Foray (1991), de que todas o la mayoría de empresas que financian los proyectos obtendrán alguna ganancia de los mismos, tal y como sucede con las pequeñas empresas que conforman los distritos industriales. De este modo, una ausencia de cooperación entre las empresas significará poca o insuficiente inversión en ciencia y tecnología.

6 “[...] En un sistema de empresa privada la única forma en que puede minimizarse este problema (de la subinversión en las actividades inventivas-innovadoras) es la realización de la investigación por grandes corporaciones con muchos proyectos en marcha, cada uno en pequeña escala en comparación con el ingreso neto de la corporación. Entonces la corporación actúa como su propia compañía de seguros. Pero ésta es claramente sólo una solución imperfecta" (Arrow, 1962, p. 158). 
Para reforzar los argumentos anteriores, en que también hacen énfasis Arrow (1962), Nelson (1959) y Zvi Griliches (1958) ${ }^{7}$ es en que los beneficios marginales privados de las mayores inversiones en ciencia y tecnología pueden ser nulos o negativos en relación con los costos de financiamiento; no obstante, mientras los beneficios marginales sociales sean mayores siempre convendrá invertir un mayor monto de recursos en conocimiento científico y tecnológico. En consecuencia, para que un proyecto de investigación beneficie a una industria o a un grupo de empresas, conviene que sea financiado por un gran número de empresas, porque todas o una buena parte será beneficiada por la derrama del conocimiento. $^{8}$

Adicionalmente, Stephanie Monjon y Patrick Waelbroeck (Link et al., 2003 , p. 1219) sostienen que los spillovers ${ }^{9}$ puros de conocimiento generan el mayor beneficio para las empresas, en comparación con la innovación cuantitativa. De hecho, encuentran que las empresas más innovadoras se benefician enormemente de la investigación colaborativa. Y es que de acuerdo con Arrow (1962, pp. 152 y 154), la producción de un bien dado bajo condiciones de incertidumbre puede describirse como un vector de opciones de bienes.

Lo importante de la teoría de los spillovers o de la derrama es que puede explicar por medio de las economías positivas externas el papel fundamental que juega la inversión en las actividades inventivas e innovadoras; tal inversión, por las mismas características que implica, no se hará en un entorno industrial en el que las empresas sólo buscan obtener altas ganancias en el corto plazo, sino más bien en un ambiente cooperativo (cuadro 1), ya que de manera individual una empresa dedicada a la producción de, por ejemplo, un solo bien no estará dispuesta a realizar grandes inversiones en ID porque eso implica que un esfuerzo individual beneficiará a varias empresas; para evitar esta situación, las empresas beneficiarias de la ID establecen acuerdos cooperativos.

\footnotetext{
${ }^{7}$ Este último, en un estudio empírico sobre los costos de investigación y rendimientos sociales en el maíz híbrido e innovaciones relacionadas, concluye: “... he estimado que la tasa de rendimiento de las inversiones públicas en una de las empresas más afortunadas del pasado ha sido muy elevada. Esto puede apoyar nuestro sentimiento intuitivo en el sentido de que los rendimientos de tales empresas en general han sido muy elevados y nuestro sentimiento de que 'la investigación es algo bueno"” (Grilliches, 1958, p. 187).

8 "El argumento anterior se ha centrado en las economías externas que abren una brecha entre el beneficio marginal privado y el beneficio marginal social derivado de la investigación básica" (Nelson, 1959, p. 146).

${ }^{9}$ Los spillovers hacen referencia a una versión más extensa y actual de las externalidades.
} 
CUADRO 1. Fines que se persiguen en las alianzas de conocimiento interempresa $y$ con otras organizaciones

\begin{tabular}{|c|c|}
\hline Estrategia & Implicaciones \\
\hline Exploratoria & $\begin{array}{l}\text { Se refiere a la búsqueda de descubrimientos y desarrollo de conocimiento que es } \\
\text { nuevo para la empresa. Los retornos de la ID exploratoria son inciertos, distantes } \\
\text { y, a veces, negativos. Como la exploración genera el potencial para la explota- } \\
\text { ción, esta estrategia incluye proyectos de largo plazo para alcanzar nuevas capaci- } \\
\text { dades y plataformas de productos. La otra cara de la estrategia es que las empre- } \\
\text { sas que invierten recursos en exploración interna desarrollan mayor capacidad } \\
\text { de absorción; habilidad para identificar, asimilar y explotar conocimiento del } \\
\text { ambiente. De esta manera, una buena cantidad de alianzas empresa-universidad } \\
\text { son de carácter exploratorio. Las universidades han servido como una fuente } \\
\text { de conocimiento científico y técnico fundacional; sin embargo, los avances con } \\
\text { potencial comercial (biotecnología, informática, investigación en materiales y } \\
\text { nanotecnología) son proyectos de investigación en las universidades pero patro- } \\
\text { cinados por la industria. }\end{array}$ \\
\hline Explotadora & $\begin{array}{l}\text { Su finalidad es refinar, extender, complementar y hacer un uso inteligente de } \\
\text { las capacidades existentes (dentro y fuera de la empresa); estas actividades son } \\
\text { generalmente cuantitativas y de corto plazo en orientación; además, la mayoría } \\
\text { de la ID industrial es explotadora. La explotación basada en las alianzas con uni- } \\
\text { versidades como socios es muy común. Para la universidad, la investigación crea } \\
\text { conocimiento que proporciona nuevos hallazgos y avances científicos potencia- } \\
\text { les. En tanto, para la empresa, este conocimiento mejora una línea de producto } \\
\text { existente que le permite un mejor despliegue en sus capacidades existentes e } \\
\text { incrementar su participación en el mercado. }\end{array}$ \\
\hline
\end{tabular}

Fuente: Elaboración propia con base en Bercovitz y Feldman (2007, pp. 932-936).

En los avances más recientes de esta perspectiva se asienta que el aumento en los gastos de ID por parte de las empresas también permite generar un entorno favorable para la creación de nuevas empresas más especializadas y avanzadas tecnológicamente. Así pues, estas nuevas aportaciones sostienen que los emprendedores no son producto de atributos de herencia genética o actitudes y aptitudes cognitivas formadas ex ante; por el contrario, los agentes emprendedores pueden formarse en un contexto económico rico en conocimiento avanzado que permita aprovechar las nuevas ideas. Estas extensiones de la teoría se han realizado por teóricos, entre los que sobresalen Paul Romer (1986) y David Audretsch (2005).

En efecto, Audretsch (2005, p. 38) destaca que el espíritu emprendedor se convierte en una respuesta endógena a las oportunidades generadas por las inversiones de las empresas y las organizaciones en nuevo conocimiento, oportunidades que surgen por la incapacidad de las empresas y organizaciones tradicionales de explotar exhaustivamente ese conocimiento. 
Asimismo, en el modelo de crecimiento endógeno de Romer (1986), el nuevo conocimiento tecnológico se asume automáticamente como un spillover; en tal sentido, la inversión en esta actividad es automáticamente aprovechada por otras empresas y agentes económicos.

Otros autores abordan las externalidades del conocimiento como redes; este concepto denota el intento por evaluar las consecuencias económicas y sociales de las externalidades y del comportamiento interdependiente de las empresas (Cimoli, 2007, p. 11). También llama la atención lo que la noción de externalidad muestra en lo negativo, que es todo el trabajo que debe hacerse, todas las inversiones necesarias para hacer relaciones calculables en la red. Así, la comprensión de las externalidades es limitada ya que uno necesita ir más allá de eso; los agentes deciden reformularse - para internalizar las externalidades - porque otras externalidades aparecen. Se sugiere el término "sobreflujo" para denotar esta imposibilidad de formación total (Callon, 1999, pp. 187-188).

Recapitulando, a la teoría de las externalidades-spillovers se le deben reconocer grandes aportaciones para la comprensión de este campo; entre éstas encontramos las propiedades económicas inherentes al conocimiento, la demostración de que la ciencia básica genera un mayor bienestar social y que su desarrollo puede dar paso a un vector de nuevos productos y procesos, así como el problema de la "gorronería" de aquellos agentes que no invierten en investigación pero que sí se benefician de ella. No obstante, todas estas categorías valiosas sugieren que la inversión en la producción de conocimiento no es muy rentable para las empresas en lo individual. En consecuencia, la pregunta central que queda sin respuesta es: ¿por qué muchas empresas sí realizan grandes inversiones en conjunto y por qué la intuición de que el desarrollo de la investigación proporciona mayor competitividad a las empresas obtiene cada vez más evidencias empíricas? La respuesta se encuentra en los hallazgos de la NEI, situación que se aborda en los siguientes apartados.

\section{La importancia del conocimiento en las empresas desde la perspectiva de la $\mathrm{NEI}^{10}$}

La observación de que la ID crea una capacidad para asimilar y explotar nuevo conocimiento proporciona una explicación inicial de por qué las empresas (sobre

\footnotetext{
${ }^{10}$ Las aportaciones de la nueva economía institucional, según Williamson (1996) y Winter (1996), no pretenden desplazar a la economía neoclásica en las explicaciones del intercambio y la produc-
} 
todo de industrias de alta tecnología) tienen que invertir en investigación básica aun considerando que la mayoría de los nuevos hallazgos y descubrimientos se origina en los dominios públicos.

Esta perspectiva del papel de la investigación básica en las empresas ofrece un punto de vista diferente de las conclusiones de Marshall (1920) Nelson (1959), Arrow (1962), Romer (1986) y Audretsch (2005), ya que a medida que el progreso tecnológico de una empresa deviene más estrechamente vinculado a los avances en la investigación básica, la empresa incrementará su investigación básica, independientemente de la diversificación de productos en el mercado. También se sugiere que no sólo la investigación básica se diversifica más sino que las empresas incrementan su ID conforme desarrollan capacidades de absorción (Cohen y Levinthal, 1990, p. 148; Cockburn y Henderson, 1998, pp.158-159).

Un tipo de conocimiento de fundamental importancia para la industria es el saber cómo (que es la parte más operativa o es simplemente conocimiento aplicado); aunque, el saber por qué también resulta central cuando se necesita comprender los procesos científicos que a veces son abstractos pero para los cuales se buscan aplicaciones industriales y su comercialización. Para acceder a los modelos teóricos que aparentemente son públicos se requieren enormes inversiones en aprendizaje antes de que la información sea de alguna utilidad para la empresa. Esta es una de las razones más fuertes para justificar la presencia de las compañías en ambientes académicos y de su participación en la investigación básica (Lundvall, 2004, pp. 24-26).

Para tener acceso al conocimiento científico (saber por qué) es necesario desarrollar actividades de ID e invertir en ciencia. Esto es válido para individuos, regiones y empresas. En realidad, los spillovers completamente libres y disponibles que se asumen en la teoría de las externalidades son mínimos si previamente no se alcanza una capacidad de absorción que permita su aprovechamiento (Lundvall, 2004; Cohen y Levinthal, 1990).

Así pues, la capacidad de absorción de una empresa es la habilidad para reconocer el valor de lo nuevo, de la información externa, su asimilación y su aplicación a fines comerciales y que resulta crítica para sus capacidades innovativas. La capacidad de absorción está en función del conocimiento previo relacionado con las actividades de la empresa (Cohen y Levinthal, 1990, p 128). Estos

ción. Por el contrario, pretenden abrir o abordar nuevas líneas de investigación que han sido desdeñadas o abandonadas por la economía ortodoxa. Esta NEI estaría representada, principalmente por la economía de los costos de transacción, la teoría de los recursos y las capacidades dinámicas, así como la teoría evolutiva (Taboada, 2004). 
autores también distinguen entre una estructura cognitiva y una estructura organizacional de la capacidad de absorción. En lo que se refiere a las cuestiones cognitivas, señalan que los estudios en las ciencias cognitivas y del comportamiento, en el nivel individual, justifican y enriquecen la presente perspectiva. Así pues, la investigación en el desarrollo de la memoria sugiere que la acumulación previa de conocimiento ${ }^{11}$ incrementa la habilidad para poner el nuevo conocimiento en la memoria (adquisición de conocimiento) y la habilidad para recordarlo y usarlo. La experiencia en desarrollar o entender una tarea de aprendizaje puede influir y mejorar el desempeño en las tareas posteriores de aprendizaje (aprender a aprender). Las capacidades de aprendizaje incluyen el desarrollo de la capacidad para asimilar el conocimiento existente, mientras que las habilidades para resolver problemas representan una capacidad para crear nuevo conocimiento (Cohen y Levinthal, 1990, pp. 129-131).

En lo que respecta al aprendizaje organizacional, los autores señalan:

i) La capacidad de absorción de las organizaciones dependerá de las capacidades de absorción de sus miembros individuales, aunque el papel de un staff interno de tecnólogos y científicos familiarizados con las necesidades idiosincrásicas de la empresa, los procedimientos organizacionales, las rutinas, las capacidades complementarias y las relaciones extramuros son decisivos para integrar exitosamente ciertas clases de conocimiento tecnológico refinado y complejo, aunque dicho concepto tampoco se constituye como la simple suma de las capacidades de los empleados.

ii) Las capacidades tenderán a desarrollarse de manera acumulativa; ${ }^{12}$ por

\footnotetext{
${ }^{11}$ La habilidad para asimilar información es una función de la riqueza de la estructura de conocimiento preexistente: el aprendizaje es acumulativo y el desempeño de lo aprendido es mayor cuando lo que es objeto de aprendizaje está relacionado con lo que se acaba de conocer. Como consecuencia, el aprendizaje es más difícil en los dominios novedosos y, más generalmente, la experiencia individual sólo cambiará cuantitativamente (Cohen y Levinthal, 1990, p. 131).

${ }^{12}$ Las organizaciones con una alta capacidad de absorción a posteriori estarán en una mejor posición para absorber el conocimiento no codificado y dependiente debido a los avances en la curva de aprendizaje de la empresa (Steenhuis y De Bruijn, 2002, en Lund, 2004). Éste es el caso, especialmente, si se han establecido conexiones fuertes. La segunda mejor solución es la de vínculos débiles combinados con una alta capacidad de absorción. Las organizaciones que, por ejemplo, han invertido fuertemente en ID o en empleados altamente capacitados, no necesitan el mismo grado de asistencia para asimilar, interpretar y utilizar el conocimiento que se está transfiriendo, en comparación con las organizaciones que han gastado menos en ID y que, por tanto, tienen una baja capacidad de absorción. La gente capacitada está dotada de habilidades tácitas para adquirir y usar el conocimiento (Lund, 2004, pp. 260-261).
} 
un lado, la capacidad de absorción acumulativa en un periodo permitirá su acumulación más eficiente en el siguiente; por el otro, la posesión de experiencia relacionada permitirá entender y evaluar mejor la importancia de los avances tecnológicos que proporcionan señales de un nuevo desarrollo.

iii) La capacidad de absorción no sólo se refiere a la adquisición o asimilación de información por una organización sino también a la habilidad de la organización para explotar la información.

iv) Tampoco la capacidad de absorción de la organización se limita a la interfase con el ambiente externo, ésta también depende de la transferencia de conocimiento a través y dentro de las subunidades de la organización. Aquí, la capacidad de absorción de la empresa depende de los individuos que permanecen en la interfase de las subunidades de la empresa y el contexto exterior. No obstante, la capacidad de absorción no se circunscribe totalmente a este tipo de expertos, más bien incluye a los que son entrenados y capacitados por los expertos. Esta característica toma mayor relevancia en un ambiente económico con mucha incertidumbre y de rápido cambio tecnológico (1990, pp. 131-136).

Adicionalmente, la empresa también tiene que resolver problemas como ponderar entre el desarrollo de las capacidades internas y las necesarias para mantenerse al día en los desarrollos externos o incluso provocarlos ella misma; es decir, al interior de una organización se tiene que resolver el asunto de no hacer redundante el conocimiento y, al mismo tiempo, mantener una interacción efectiva entre los departamentos. Al exterior, la empresa debe contar con expertos para valorar el conocimiento que se está generando y que puede venir de distintos campos, lo que exige a la empresa contar con un equipo multidisciplinario que le permita desarrollar mayores capacidades de absorción en ambos sentidos.

Por el hecho de que la producción de conocimiento científico requiere grandes inversiones, porque genera derrama y debido a su difícil comprensión, las empresas, al tiempo de invertir para desarrollar capacidades básicas internamente, también se vinculan con otras empresas u organizaciones (preponderantemente con las universidades) para monitorear, entender y explotar los nuevos descubrimientos científicos.

Debido a que muy poco conocimiento es completamente público, aun la información de saber qué puede ser imposible de acceder por parte de aquellos 
que no están conectados en las telecomunicaciones o en las redes sociales. ${ }^{13} \mathrm{El}$ científico y otros tipos de conocimiento complejo pueden ser perfectamente accesibles, en principio, pero para tener acceso a ellos de forma efectiva los usuarios tienen que invertir en la construcción de capacidades de absorción (Lundvall, 2004; Cohen y Levinthal, 1990).

Otro elemento importante de por qué las empresas deben invertir en ciencia básica o en conocimiento científico es que las organizaciones necesitan tener competencias especializadas y encontrar a los expertos más competentes y confiables que les permitan estar vinculadas con científicos o especialistas de otras organizaciones. Estas relaciones sociales y personales no son públicas; tampoco es posible transferirlas (no pueden ser compradas o vendidas en el mercado) (Lundvall, 2004, p. 27).

Un aspecto muy importante y que está presente en la capacidad de absorción de las empresas es la trayectoria dependiente, lo que quiere decir que mucho de lo que ahora o en el futuro se haga depende de lo que se hizo previamente. De este modo, si la empresa o la organización no desarrolló capacidades de absorción desde un inicio, difícilmente las desarrollará posteriormente o, si lo hace, ello le resultará muy costoso. Este asunto es ampliamente abordado y demostrado tanto por Cohen y Levinthal (1990) como por Shane y Stuart (2002). Adicionalmente, los primeros señalan que las organizaciones que desarrollan amplias capacidades de absorción suelen ser más proactivas ante la incertidumbre y los cambios rápidos en el estado del conocimiento; por el contrario, las organizaciones con nulas o pocas capacidades de absorción son más reactivas.

Shane y Stuart (2002, p. 158) sugieren que los nuevos proyectos que carecen de las dotaciones iniciales de los recursos necesarios podrían desarrollar estructuras, procesos internos y recursos humanos inferiores en relación con sus competidores, ${ }^{14}$ y de este modo, desarrollarían una reputación de baja calidad que puede ser muy difícil de superar.

\footnotetext{
${ }^{13}$ En general, las redes tienen dos funciones que facilitan el reforzamiento de los contratos implícitos y la selección de los socios confiables, respectivamente. Primero, la red es un mecanismo para sancionar a los agentes que se comportaron de manera oportunista; segundo, la red delinea la trayectoria a lo largo de la cual la información es retransmitida entre sus miembros. Los agentes conocerán el comportamiento anerior de los otros miembros de la red dentro de sus esferas de información. Adicionalmente, los vínculos directos e indirectos (mediante un intermediario o un tercero) son muy importantes para facilitar el intercambio y el nivel creciente de confianza en una relación (Shane y Stuart, 2002, pp. 155-157).

${ }^{14}$ La presencia de vínculos directos e indirectos con los inversionistas de los proyectos (en las start-ups) en la búsqueda de financiamiento para la empresa, claramente disminuye el riesgo de
} 
La teoría de la empresa basada en los recursos, asume que la competencia de la empresa determina las direcciones en las cuales ésta expande sus actividades (Penrose, 1959, en Lundvall, 2004). Es la especificidad de la base del conocimiento lo que delinea el patrón específico de crecimiento económico. Este modelo ha sido ampliado a una perspectiva más dinámica (capacidades dinámicas) caracterizada por una continua creación de nuevas competencias dentro de la empresa y también apunta a la necesidad de desarrollar organizaciones de aprendizaje (Lundvall, 2004; Teece et al., 1997). Adicionalmente, Shane y Stuart (2002, p. 169) señalan que debido a que los contratos son, por lo general, incompletos en las relaciones para producir conocimiento y en los proyectos financieros, las teorías basadas en las redes tienen mucho que contribuir para entender los diferentes fenómenos. Por otro lado, mucho del conocimiento detallado de las rutinas y los objetivos organizacionales que le permiten a una empresa y a su laboratorio de ID funcionar es tácito (Cohen y Levinthal, 1990, p. 135).

Lund (2004, p. 258), retomando a otros autores, señala que con el fin de adquirir, transferir y utilizar el conocimiento, especialmente el no codificado (tácito), las instituciones u organizaciones utilizan una combinación de capacidad de absorción interna y de vínculos fuertes que son complementarios e importantes en el proceso de la innovación en términos de sus propios resultados y que contribuyen al mejoramiento de la curva de aprendizaje de la empresa.

Este componente tácito del conocimiento requiere una estrecha interacción entre las organizaciones que participan en el aprovechamiento de conocimientos. Dicha interacción va más allá de la simple firma de acuerdos o contratos para la transferencia de conocimiento científico y tecnológico. La parte tácita es, en buena medida, la que hace inviables los contratos formales para compartir conocimiento, ya que por las mismas características de éste su transferencia mediante contratos implicaría el diseño, la gestión y la empresa de $n$ contratos que resultarían muy costosos para los agentes.

Lo tácito también se relaciona con la transferencia y el carácter público del conocimiento. Al respecto, se ha sostenido que a mayor conocimiento tácito, más difícil es compartirlo entre la gente, las empresas y las regiones. El conocimiento tácito es, pues, conocimiento que no ha sido documentado o hecho explícito por quien lo usa y lo controla ${ }^{15}$ (Lundvall, 2004, p. 28). En este contexto, Ajay

mortalidad en los primeros años e incrementa la probabilidad de que las start-ups obtengan financiamiento externo (Shane y Stuart, 2002, p. 168).

${ }^{15}$ Una cuestión importante en este contexto es cuánto esfuerzo se requiere para codificar el conocimiento. Si se logra la codificación, el conocimiento puede ser potencialmente compartido, mientras 
Agrawal (2001, p. 291) señala que en el nivel conceptual es interesante hacer notar que la transferencia de conocimiento tácito, el cual es costoso o imposible de codificar, está en el corazón de la mayoría de los trabajos de investigación que abordan la cuestión de la cooperación relacionada con el conocimiento. En concordancia, Agrawal menciona que la conectividad entre los agentes del conocimiento es importante sólo porque el conocimiento relacionado con una invención no es completamente transferido en la forma codificada de patentes o publicaciones, por lo que requiere algunas formas de interacción entre el inventor y la empresa receptora. Asimismo, Cockburn y Henderson (1998, p. 158) señalan que la conectividad es un factor clave para que la empresa maneje habilidades de reconocimiento y uso de los desarrollos de frontera del conocimiento.

La bibliografía más reciente sobre la innovación enfatiza que la producción de conocimiento es un proceso interactivo en el que las empresas interactúan con los clientes, los proveedores (Cohen y Levinthal, 1990, p. 134) y las instituciones de conocimiento. De este modo, el movimiento hacia las organizaciones de aprendizaje se refleja en los cambios tanto en la organización interna de la empresa como en las relaciones interempresa. Dentro de las empresas, la acelerada tasa de cambio provoca que las jerarquías multinivel y los límites estrictos entre las funciones sean ineficientes. Esto hace que la descentralización de responsabilidades hacia los empleados de menor nivel y la formación de equipos multifuncionales sea una necesidad (Lundvall, 2004, pp. 31-32).

Cohen y Levinthal (1990, p. 149) mencionan que se ha observado que los proyectos cooperativos iniciados para desarrollar investigación básica o aplicada han estado sujetos a mayor presión para que se alcancen los objetivos en un menor tiempo. Además, quienes están procurando alentar los proyectos de investigación cooperativa, en los campos de rápido avance, deben reconocer que la participación directa en el proyecto debe representar sólo una porción de los recursos que retornarán del mismo proyecto. Las empresas participantes también tienen que estar preparadas para invertir internamente en la capacidad de absorción que les permitirá una explotación efectiva del conocimiento que resulte del proyecto cooperativo.

que el conocimiento no codificado permanece individual, al menos, hasta que éste pueda aprenderse en interacción directa con su poseedor. Lo que ha sido considerado como atributos importantes del conocimiento (público/privado; codificado/tácito) sugiere que puede haber marcadas diferencias entre varios sectores respecto a su base de conocimiento. Algunos sectores basados en la ciencia desempeñan sus actividades utilizando conocimiento codificado, mientras que otros operan y compiten auxiliándose del conocimiento tácito. Pero no existen casos puros. Aun en los sectores fuertemente basados en la ciencia, el conocimiento tácito será un elemento clave en su posición competitiva (Lundvall, 2004, p. 29). 
En otro orden de ideas, la creciente especialización en la producción de conocimiento hace la mediación más decisiva para toda la economía. Esto se refleja en el hecho de que los negocios intensivos en conocimiento, un sector directamente involucrado en la producción y venta de conocimiento, están entre los sectores de más rápido crecimiento en los países de la OCDE. Una segunda forma de mediar con este tipo de conocimiento es involucrarse en un proceso de aprendizaje con sus portadores, por ejemplo, por medio de la cooperación entre la gente y las organizaciones para resolver problemas compartidos. Un tercer modo de obtener este tipo de conocimiento es contratar expertos o asumir que la organización controle el conocimiento (Lundvall, 2004, p. 35).

Agrawal, después de hacer una exploración de los trabajos que abordan la colaboración de las empresas con la universidad y de resaltar las características de las empresas que se involucran en ese proyecto, sugiere que la mayoría de trabajos aborda el problema de cómo fortalecer y ampliar las capacidades de absorción de las empresas. De tal suerte que las compañías deben considerar varios mecanismos de asignación de recursos para incrementar la capacidad de absorción; tales mecanismos pueden ser: $i$ ) contratar y reclutar estudiantes graduados; ii) contratar investigadores académicos como consultores; iii) modificar los incentivos internos para publicar o patentar; $i v$ ) financiar investigación universitaria; $v$ ) participar en consorcios de investigación; vi) enviar a los científicos de las compañías a los laboratorios universitarios como científicos visitantes (este punto también lo abordan Cohen y Levinthal, 1990), y vii) involucrarse en investigación colaborativa con los científicos de la universidad que puede dar como resultados la publicación o las patentes compartidas (Agrawal, 2001, pp. 290-291).

Una vez considerados los aspectos que las empresas toman en cuenta para involucrarse en la investigación científica y complementar sus capacidades y habilidades colaborando estrechamente con las universidades, en el siguiente apartado se explora lo que sucede al interior de estas últimas.

\section{II. ¿CÓMO EXPLICAR LA PARTICIPACIÓN DE LAS UNIVERSIDADES EN LA ACTIVIDAD ECONÓMICA?}

Aunque la universidad siempre ha participado en la producción de riqueza, aun de manera indirecta - por medio de sus graduados - , también desde hace algunas décadas ya transfería tecnología a las empresas de una manera lineal. ${ }^{16}$

\footnotetext{
${ }^{16}$ La transferencia lineal se entiende como el mecanismo mediante el cual las universidades o los
} 
Al respecto, Etzkowitz (2003, pp. 112-113) señala que el modelo lineal es todavía una ruta viable para la innovación, pues es una característica fructífera e inevitable de muchos proyectos de investigación académica, de la industria y del gobierno; además, existe transferencia de tecnología y formación de empresas desde estas fuentes. Sin embargo, el modelo lineal, más que operar de manera automática requiere complementaridad y reforzamiento mediante formatos lineales ex ante y ex post, incluyendo la reversa lineal, la lineal asistida y los modos interactivos de innovación. En este contexto, la linealidad de reversa comienza desde las necesidades comerciales y sociales. Paralelamente, los modos lineales asistidos se comparten crecientemente con la inserción de las capacidades de intermediación para la transferencia de tecnología, la incubación y los proyectos dentro y entre las organizaciones.

Por otro lado, el modelo del emprendedor schumpeteriano se ha extendido más allá de la esfera de los negocios alcanzando a la educación y al gobierno; y también ha evolucionado de lo individual a lo colectivo. Por tanto, la universidad contemporánea es una amalgama de intereses en docencia e investigación, de lo aplicado y de lo básico, así como de lo empresarial y lo escolar. Todos estos elementos coexisten en una tensión creativa que continuamente deviene en conflicto que tiene como resultados el compromiso y el cambio normativo en el que elementos ideológicos aparentemente opuestos, como el espíritu emprendedor y la extensión del conocimiento, son reconciliables (Etzkowitz, et al., 2000, pp. 325-326).

De hecho, la universidad empresarial sigue un modelo interactivo de innovación que combina modos lineales y lineales de reversa. Así pues, la universidad empresarial tiene capacidades de interfase tales como la vinculación, las oficinas de transferencia y las facilidades de incubadora para gestionar y comercializar el conocimiento producido. Tales estructuras organizacionales de interfase también desempeñan una función lineal de reversa al conectar a la universidad con los problemas externos, las fuentes de conocimiento y las empresas que buscan los recursos académicos (Etzkowitz, 2003, p. 113; Meyer-Krahmer y Schmoch, 1998, p. 939).

La identificación, la creación y la comercialización de la propiedad intelectual están convertidos ya en objetivos institucionales en muchos sistemas académicos. En efecto, la universidad emprendedora abarcaría una tercera misión

centros de investigación trasladan su conocimiento científico y tecnológico a las empresas sin que tenga lugar algún tipo de realimentación; es decir, existen un emisor y un receptor explícitos. 
que estaría vinculada con el desarrollo económico. ${ }^{17}$ En muchas universidades, las actividades empresariales se alientan con el objetivo de mejorar el entorno económico regional o nacional, pero también persiguiendo algún beneficio pecuniario o financiero. Sin embargo, una parte importante de los académicos en las universidades observan el paradigma empresarial como una amenaza a las funciones tradicionales (docencia e investigación), temiendo que un elevado interés pecuniario causará a la universidad la pérdida de su función como una institución crítica independiente de la sociedad (Blumenthal et al., 1986; Etzkowitz et al., 2000, pp. 313-314; Etzkowitz, 2003, pp. 115-117; Welsh et al., 2008).

Además de los conflictos de intereses que existen al interior de las universidades, al exterior algunas empresas muestran preocupación por las nuevas empresas que surgen como competidoras potenciales pero que son asistidas por la universidad. Tales empresas presionan para que la universidad se limite a sus funciones tradicionales de docencia e investigación (Etzkowitz et al., 2000, p. 314).

Aceptando que las universidades son una importante fuente de nuevo conocimiento, especialmente en las áreas de ciencia y tecnología (Agrawal, 2001, p. 285), la universidad como una institución que produce y disemina el conocimiento desempeña un papel más importante en la innovación industrial. De este modo, en una economía basada en el conocimiento, la universidad se convierte en un elemento clave de los procesos de innovación como proveedor de capital humano y como piso para la creación de nuevas empresas científicas o tecnológicas.

Entre las empresas y las universidades se tejen redes institucionales que tienen como finalidad ya sea compartir y generar nuevo conocimiento, a veces de aplicabilidad industrial, o simplemente explotar el conocimiento originado y difundido por las universidades. Esas redes pueden aparecer a partir de vínculos informales (Casas, 2001) o lazos débiles (Shane y Stuart, 2002; Lund, 2004). No obstante, la participación de científicos y académicos en tales redes tiene por objeto buscar la aplicabilidad de un invento o de una innovación radical, pero también se busca una ganancia económica. Entonces, a partir de los motivos que impulsan las interacciones universidad-empresa se genera un intenso debate en cuanto a si el conocimiento debe ser completamente público y libre o si puede ser objeto de comercialización mediante el patentamiento y el licenciamiento previendo algún beneficio pecuniario (Blumenthal et al., 1986). Sin embargo,

\footnotetext{
${ }^{17}$ Los gobiernos de muchos países (sobre todo los más desarrollados) centran sus decisiones para lograr un mayor crecimiento económico en el potencial de la universidad como un recurso de fortalecimiento de la capacidad innovadora y para crear un régimen de desarrollo económico basado en el conocimiento científico (Etzkowitz, et al., 2000, p. 314).
} 
los investigadores que llevan a cabo transferencia de tecnología, se enfrentan a varios dilemas, tales como la cultura organizacional diferente o el involucramiento con las patentes, las publicaciones y los secretos industriales (Rahm, 1994, p. 277).

Dado lo anterior, de acuerdo con Etzkowitz y Kemelgor (1988, en Etzkowitz, 2003, p. 111) los grupos de investigación funcionan como empresas, careciendo sólo de un motivo pecuniario directo para hacerlos realmente una compañía. Conforme el tamaño del grupo de investigación crece, los profesores que inicialmente estaban haciendo investigación se obligan a dedicar, virtualmente, tiempo completo a las tareas organizacionales. De ordinario, los investigadores en esta situación se describen como si estuvieran dirigiendo un pequeño negocio. Por consiguiente, para continuar con el nivel competitivo frente a los pares, estos grupos de investigación tienen que mantener un momento organizacional durante su actividad de investigación. Una vez alcanzada esta meta, es muy difícil funcionar de vuelta como investigador individual, por tanto, cada esfuerzo se hace para sostener el liderazgo de un grupo.

Pero, más allá de las cuasiempresas, la universidad también asiste a una transformación organizativa, pues se ha pasado de un enfoque individual a uno de grupo en las tres funciones sustantivas. El cambio es más notorio en las ciencias donde los grupos de investigación han remplazado la dupla profesor-estudiante como la forma organizativa principal. Existe una transformación similar en la misión del desarrollo económico y social en el que la universidad desempeña un papel más abierto como organizadora de la innovación regional (Etzkowitz, 2003, p. 111).

La universidad empresarial requiere una capacidad fortalecida para la inteligencia, el monitoreo y la negociación con las otras esferas institucionales, especialmente la industria y el gobierno. Más allá de la habilidad del grupo líder de la universidad para vincularse con sus contrapartes, una capacidad de mediano nivel otorga a la universidad la habilidad suficiente para identificar la confluencia de intereses entre las organizaciones externas y su contraparte académica. Los especialistas de la interfase realizan introducciones, organizan discusiones, negocian contratos; es decir, actúan de intermediarios para facilitar la interacción con los socios. Aunque a este personal técnico también se le asignan responsabilidades para valorar la salida comercial de los resultados de la investigación, las capacidades centralizadas de interfase (por ejemplo, oficinas de transferencia de tecnología) asumen una función de liderazgo en las primeras etapas de la introducción del paradigma empresarial (Etzkowitz et al., 2000, p. 316). 
CUADRO 2. Expansión de las misiones de la universidad

\begin{tabular}{|c|c|c|}
\hline Enseñanza & Investigación & Empresarial \\
\hline $\begin{array}{l}\text { - Preservación y } \\
\text { diseminación del } \\
\text { conocimiento. } \\
\text { - Las nuevas misiones } \\
\text { generan conflicto de } \\
\text { intereses y controversias. }\end{array}$ & $\begin{array}{l}\text { - Primera revolución } \\
\text { académica. } \\
\text { - Dos misiones de la } \\
\text { universidad: docencia e } \\
\text { investigación. }\end{array}$ & $\begin{array}{l}\text { - Segunda revolución } \\
\text { académica. } \\
\text { - Tercera misión: desarrollo } \\
\text { económico y social. } \\
\text { - Las misiones anteriores } \\
\text { continúan. }\end{array}$ \\
\hline
\end{tabular}

Fuente: Elaboración propia con base en Etzkowitz (2003, p. 110).

A pesar de que históricamente la universidad había participado en la producción siendo proveedora de mano de obra capacitada y especializada, ahora, en una vinculación más estrecha con la industria y más ampliamente con las actividades económicas, las organizaciones de este tipo también necesitan desarrollar capacidades, en este caso, de vinculación con las empresas. Esto lleva a que las universidades estén más involucradas en funciones que tradicionalmente eran de las empresas privadas. En consecuencia, más allá del establecimiento de lazos con las organizaciones existentes la universidad, como emprendedora, también desarrolla capacidades para asistir la creación de nuevas organizaciones. Esta trayectoria toma lugar como la formación de empresas basadas en la investigación académica o la formación de organizaciones regionales (Etzkowitz et al., 2000, p. 317).

La academia se ha convertido, pues, en emprendedora tanto en su dinámica interna como mediante las conexiones externas hechas con las empresas de negocios para los contratos de investigación y la transferencia de conocimiento y tecnología. Sin embargo, todavía la mayor parte de los científicos académicos y las universidades que hacen investigación se abstienen de comercializarla, a pesar de que no se ha demostrado que la función emprendedora haya provocado un sesgo nítido hacia la investigación comercializable. Por el contrario, esta nueva función ha contribuido a fortalecer la investigación al tiempo de obtener mayores ingresos por la apropiabilidad del conocimiento (Etzkowitz, 2003, pp. 109 y 115).

Una parte importante de los trabajos referidos a la transferencia del conocimiento universidad-industria se ha relacionado con el registro de patentes y su licenciamiento. No obstante, las políticas que afectan el comercio del conocimiento científico y su aplicación comercial, que no es patentada y que no fluye mediante las oficinas de transferencia de tecnología, han sido largamente pasadas por alto. Además, las universidades tienen menos experiencia para tratar con el sector privado y también están sujetas a mayores restricciones debido a sus objetivos y respon- 
sabilidades tradicionales, que van más allá de la obtención de ganancias. Entonces, las universidades se comportan de manera diferente de las empresas, aun cuando éstas estén involucradas en transacciones de negocios. En esta perspectiva, nuestro entendimiento de las interacciones universidad-empresa está menos desarrollado que las tradicionales interacciones empresa-empresa, y de este modo, el análisis referente a la transferencia de conocimiento universidad-industria no puede confiarse a las hipótesis de la interacción empresa-empresa (Agrawal, 2001, p. 294).

Finalmente, aunque las aportaciones de Etzkowitz han sido decisivas para explicar la participación de las universidades directamente en las actividades relacionadas con la creación y la gestión de la riqueza, es necesario profundizar y tomar en cuenta otros elementos que dejan fuera los trabajos del autor, pero que son muy relevantes para integrar una postura teórica más completa y con un sustrato más económico, preocupación que está implícita en este artículo. No obstante, en el presente documento también se acepta que la universidad de nuestro tiempo es de mayor relevancia para la sociedad, pues a sus funciones tradicionales se agrega la del desarrollo económico. Así es que si la cobertura universitaria no se extiende y si los recursos para financiar sus funciones no se incrementan, de alguna manera esas decisiones, sin duda, tendrán sus efectos directos en menores tasas de crecimiento económico y de bienestar social.

\section{LA COLABORACIÓN EMPRESA-UNIVERSIDAD EXPLICADA CON LOS INSTRUMENTOS TEÓRICOS DE LA NEI}

Se establece que con las herramientas teóricas y metodológicas de la NEI se puede explicar la colaboración empresa-universidad. Desde las tres principales teorías (costos de transacción, de los recursos-capacidades y evolutiva) se encuentran elementos de síntesis y de complementariedad (Taboada, 2004).

Retomando a Williamson (1975, 1985 y 1996), se entendería que los acuerdos colaborativos entre empresas y universidades se establecen con la finalidad de reducir los altos costos de transacción explícitos e implícitos en los proyectos de investigación y desarrollo que por sus propiedades inherentes pueden ser prohibitivos para una sola organización. Sin embargo, los acuerdos colaborativos deben regularse por los contratos (formales o informales) que se establecen para evitar o mitigar el riesgo de comportamiento oportunista por una de las partes. Asimismo, debido a que en la teoría de los costos de transacción también se asume la hipótesis de racionalidad limitada, ello implica que deben establecerse las alianzas para potenciar el conocimiento. 
Una de las principales críticas que se le hacen a la teoría de los costos de transacción surge en el mismo corazón de la NEI ya que, desde la perspectiva de la economía de los recursos y las capacidades, las características de la investigación no permiten establecer contratos rígidos, o en todo caso éstos tendrían que ser muy flexibles o incompletos (Kay, 1988; Foray, 1991), y antes de considerar los costos de transacción las organizaciones deciden vincularse con base en su dotación de activos tangibles e intangibles, buscando la complementariedad de los mismos y la formación de nuevas capacidades. Dentro de las extensiones recientes de esta perspectiva teórica se señala que las organizaciones no sólo buscan las alianzas o la colaboración con fines puramente de complementariedad de activos, sino que también los acuerdos se establecen en función de la coincidencia en los niveles de aspiraciones (Lucas, 2007). En este contexto puede ser más viable el establecimiento de alianzas entre las organizaciones que comparten aspectos idiosincráticos.

Lo anterior permite establecer que en un contexto coevolutivo (Nelson, 2008) las empresas que aspiran a tener una base importante de conocimiento en el futuro, establecen vínculos con las organizaciones que aspiran a transferir una parte mayúscula de su producción de conocimientos. Lo desafiante de esta postura es que en el presente ninguno de los agentes puede tener una gran dotación de activos, basta con que los objetivos del futuro esperado coincidan y se acoplen. Si esta hipótesis encuentra suficientes evidencias a su favor, de antemano abre enormes oportunidades para la vinculación entre empresas y universidades, de economías en las que dicho fenómeno recién comienza a tomar fuerza pues si las aspiraciones de empresas y universidades coinciden, su futuro puede ser promisorio.

Frente al análisis estático de los costos de transacción y la teoría de los recursos y las capacidades, en los últimos años se han expandido las herramientas de análisis al incluir las capacidades dinámicas y elementos de la teoría evolutiva. De este modo, las capacidades dinámicas implican que para acceder al conocimiento es necesario tener fortalezas a priori; además, conforme la variable del tiempo toma relevancia, las capacidades de las organizaciones van cambiando en concordancia con el medio en el que se desempeñan dichas organizaciones, sin desdeñar la propiedad acumulativa del conocimiento.

Por otro lado, dada la gran flexibilidad y lo incompleto de los contratos, sobre todo por el componente tácito o no codificado del conocimiento, es necesario incorporar la categoría de la confianza en los acuerdos colaborativos empresauniversidad. Esa confianza implica que para alcanzar una colaboración exitosa, los agentes deben evitar un comportamiento oportunista, porque si se incurre en 
esa conducta, el agente tendrá una probabilidad menor de ser socio en otro acuerdo cooperativo debido a que en las organizaciones también hay aprendizaje. Por consiguiente, en un ambiente de confianza mutua existirán más posibilidades de compartir el conocimiento tácito y, por tanto, la colaboración se fortalece.

En otro sentido, el fenómeno de la colaboración empresa-universidad puede seguir ampliándose por dos razones: la primera está relacionada con la economía del conocimiento y una característica de ésta es que las empresas estarán cada vez más necesitadas de nuevos conocimientos científicos y tecnológicos; para satisfacer esa necesidad recurrirán a las universidades y a los centros de investigación. En segundo lugar, las universidades, orilladas por las circunstancias, se verán cada vez más involucradas en el desarrollo económico y, por tanto, la transferencia de conocimiento permitirá el desarrollo de verdaderos mercados de la propiedad intelectual.

Juntas, empresas y universidades comienzan a desarrollar nuevas rutinas de colaboración y de manejo estratégico de la información y el conocimiento. En efecto, empresas y universidades coevolucionan en una economía en la que el conocimiento científico y tecnológico es sinónimo de competitividad.

\section{Colaboración empresa-universidad como coordinación híbrida}

Desde otro ángulo, tanto la empresa como la universidad convergen en funciones de coordinación económica que podrían considerarse híbridas, pues como lo señalan Williamson (1975 y 1985) y García et al. (2004), entre el mercado y la jerarquía (empresa) existen mecanismos intermedios o híbridos como las alianzas estratégicas y/o los acuerdos colaborativos, las franquicias y la subcontratación. En efecto, claramente se observa que la colaboración empresa-universidad es una organización híbrida. Sin embargo, la nueva función de desarrollo económico de la universidad o, lo que es lo mismo, la pretensión de comercializar el conocimiento por medio de la propiedad intelectual hace de esta organización una protoempresa; desde el punto de vista de Etzkowitz (2003), en el corazón de la universidad los grupos de investigación actúan como "cuasiempresas".

En contrapartida, muchas empresas de los sectores intensivos en conocimiento han hecho suya la función de investigar y generar o proponer nuevas líneas de investigación, actividades que, en principio, eran exclusivas de las universidades o de los centros de investigación. En este sentido, al igual que las protoempresas, las empresas de este tipo podrían considerarse protouniversidades. Esto a pesar de que las universidades y las empresas que establezcan acuerdos colabo- 
rativos para compartir e intercambiar conocimiento puedan ser pocas en comparación con el conjunto de la economía; sin embargo, éste es un fenómeno que va en ascenso y parece ser irreversible. Aunque es de reconocer que hacen falta indicadores confiables y consistentes que permitan medir el grado de colaboración de mejor manera, como se menciona en algunos pasajes de este artículo.

Para determinar teóricamente el punto en el que se encuentra una organización en el continuo (ver esquema) bastaría con obtener la proporción de actividades que se coordinan mediante los precios de mercado y la proporción coordinada de manera centralizada. De tal forma, podría decirse que alguna organización tiende hacia uno de los dos extremos.

En realidad, el mundo económico está compuesto por una vasta lista de mecanismos coordinadores que se ubican entre los extremos. La misma universidad y los centros de investigación, al cobrar cuotas a sus estudiantes, al realizar investigación por contrato y al centralizar las decisiones sobre unos recursos dados, están tomando funciones que tradicionalmente se le atribuían a las empresas; sólo se distinguían de éstas porque no tenían como objeto principal obtener algún beneficio pecuniario directo. Aunque actualmente al comercializar la propiedad intelectual estas organizaciones realizan actividades muy de empresa debido a que explícitamente se busca una ganancia.

Por último, empresas y universidades, por medio de la colaboración científica y tecnológica, logran conciliar intereses conformando una organización híbrida que no está completamente centralizada, pero tampoco gobernada por los precios. Esta cooperación puede distinguirse como una organización más flexible y dinámica, pues el aprendizaje registrado en el tiempo actúa como una condición para el movimiento de esta organización en el continuo.

Formas de coordinación de la actividad económica

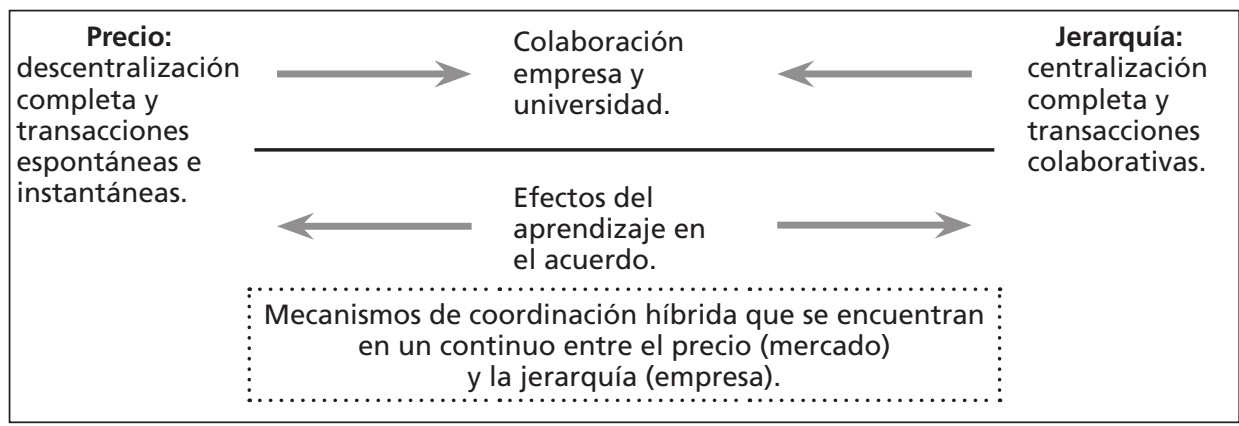

Fuente: Elaboración propia. 


\section{PROBlemas TEÓRICOS Y OPORTUNIDADES DE INVESTIGACIÓN FUTURA DE LA COLABORACIÓN EMPRESA-UNIVERSIDAD}

No obstante que muchos autores coinciden en que la colaboración es algo bueno y que es económicamente benéfica, no está exenta de algunos problemas explícitos e implícitos. Los trabajos de Welsh et al. (2008) y de Baldini (2008, p. 290) ilustran claramente estos resultados contradictorios; en especial, el segundo señala que aun en la actualidad, la mayor parte de la bibliografía continúa siendo anecdótica y especulativa. Por su parte, los otros autores establecen que es frecuente encontrar aspectos benéficos de las relaciones industria-universidad que pueden ser muy problemáticos, pero también se pueden encontrar efectos perjudiciales y, por tanto, problemáticos (véase Welsh et al., 2008, p. 1855). Particularmente, en la cooperación empresa-universidad podemos encontrar los siguientes desafíos.

El primer problema que salta a la vista, acerca del cual existen pocas contribuciones desde la perspectiva económica, se refiere a los derechos de propiedad de, por ejemplo, una patente generada por el desarrollo de un proyecto conjunto. Sin duda, aquí una situación delicada es cómo distribuir equitativamente las probables regalías o ganancias (Katz y Martin, 1997; Ducor, 2000). Otro asunto que preocupa se relaciona con el tiempo de la difusión de los resultados de la investigación; es decir, puede darse una controversia (que requiere grandes esfuerzos de negociación) puesto que la empresa deseará mantener en secrecía los hallazgos o, en su caso, apropiárselos inmediatamente por medio de una patente o el secreto industrial; mientras tanto, los investigadores miembros de la universidad desearán difundir los resultados a la brevedad publicando algún artículo específico (Welsh et al., 2008). Salvar estos problemas no es una cuestión sencilla y poco se ha escrito al respecto; por tanto, se requieren mayores esfuerzos de investigación para buscar y encontrar una solución que se adecue a los anhelos de cada institución.

En segundo lugar, tanto empresa como universidad, de manera recíproca, al vincularse asumen que se debe buscar una utilidad comercial a los hallazgos de los proyectos de investigación que se financian y desarrollan de manera conjunta; ante esto, uno de los primeros productos o procesos puede estar representado por una patente, pero ésta se relaciona directamente con la innovación (algo que se puede llevar a escala industrial). Esto representa un problema para las universidades ya que a posteriori éstas desearán impulsar la investigación aplicada y tecnológica por encima de la básica (Baldini, 2008, 
p. 295), ${ }^{18}$ lo que en el largo plazo puede ser contraproducente. El problema se agrava para las universidades de América Latina debido a que la investigación básica está rezagada; entonces, la nueva tendencia podría perpetuar ese problema, orillando a las universidades latinoamericanas a ser más dependientes de la investigación básica de otras universidades de Estados Unidos y de Europa, principalmente. ${ }^{19}$ En este sentido, y a pesar de que algunas investigaciones han abordado el problema, los resultados todavía son controvertidos (Blumenthal et al., 1986; Rahm, 1994; Welsh et al., 2008), por lo que se requiere más investigación para aclarar el dilema.

Un tercer problema surge cuando no hay medidas o estrategias complementarias que limiten el poder monopólico y/u oligopólico en la colaboración empresauniversidad, ya que puede favorecerse un entorno económico menos competitivo. Por ejemplo, suponiendo que las universidades unen esfuerzos y establecen un mercado de conocimiento y de tecnología avanzada, donde las patentes serían los productos a ofrecer y demandar, lo más probable es que sean las grandes empresas las que se beneficien en mayor medida de este nuevo conocimiento. ${ }^{20}$

Al respecto, Burrone y Singh mencionan por lo menos seis barreras que enfrentan las pequeñas y medianas empresas para utilizar el sistema de propiedad intelectual; entre éstas destacan las siguientes: $a$ ) conocimiento limitado del sistema al que no se da importancia como una estrategia para lograr una mayor competitividad, además de los costos implícitos por usarlo y la complejidad que representa para las pequeñas empresas; $b$ ) los costos para gestionar una patente son elevados y existe la percepción de que el sistema es de poca utilidad; $c$ ) ausencia de medidas gubernamentales que auxilien a las pequeñas empresas en el registro de patentes, y d) los retrasos en la obtención de una patente generan una

${ }^{18}$ Concretamente, el autor señala que puede haber un efecto sustitución entre las patentes y las publicaciones, al mismo tiempo que se reduce la calidad de las publicaciones y declina la calidad de las patentes conforme las actividades de patentamiento se incrementan.

${ }^{19}$ Por desgracia, las investigaciones sobre la vinculación universidad-empresa en América Latina poco se han interesado en abordar estas cuestiones y los trabajos se han desarrollado sobre todo en una perspectiva sociológica (véase, por ejemplo, Arellano, 1996; Dutrénit, 1996; Casas, 2001; Luna, 2003). Adicionalmente, cuando uno asiste a los actos académicos de difusión y divulgación de los resultados de las investigaciones, éstos suelen ser muy descriptivos, en el mejor de los casos apuntan a buscar evidencias empíricas de las teorías propuestas en otros ámbitos, cosa que es necesaria pero muy insuficiente para aportar nuevas cosas desde acá. Un ejercicio heurístico, a partir de las investigaciones realizadas en América Latina sobre la colaboración empresa-universidad, seguramente aportaría resultados de gran valía en este sentido. En pocas palabras, se puede decir que el esfuerzo por desarrollar teoría en América Latina y, más concretamente en México, ha sido deplorable.

${ }^{20}$ El trabajo de Merritt (2007) obtiene algunas evidencias empíricas para este problema. 
mayor incertidumbre en las empresas debido a que se retrasa también la posibilidad de encontrar interesados potenciales que deseen licencias para la explotación de esa invención (Burrone y Singh, 2004, pp. 7-8). En efecto, los riesgos de provocar una mayor concentración de mercado son reales. Desafortunadamente, los riesgos para las economías en desarrollo son mayores, pues los mercados son menos competitivos.

Cuando la colaboración en investigación es extensa y se obtienen resultados importantes de ella, se justifica el establecimiento de una estructura de gobernabilidad (actividades administrativas, de monitoreo, de enlace, etcétera) que mantenga la viabilidad de las colaboraciones. Sin embargo, cuando la actividad inventiva e innovadora es insignificante, los costos de mantener una estructura burocrática pueden ser mayores que los beneficios. Por ejemplo, en México se puede llegar al extremo de que alguna universidad establezca una oficina de transferencia de tecnología sin tecnología para transferir. Tal situación representa un cuarto problema.

Finalmente, desde el punto de vista metodológico, existe una vasta bibliografía que utiliza los artículos y las patentes (coautorías y coinventos) como indicadores para medir o monitorear la actividad colaborativa (Lissoni y Montobbio, 2008; Breschi et al., 2005; Ducor, 2000). No obstante, esos indicadores son parciales y sólo reflejan la parte más tangible de la investigación sin considerar una parte muy importante de la colaboración realizada por medio del intercambio tácito (Katz y Martin, 1997); pero peor aún, existe un sesgo por campos de conocimiento, ya que estos indicadores suelen ser más utilizados en las ciencias naturales. Por ejemplo, en las ciencias sociales el indicador de patentes no tiene sentido y deben buscarse otros indicadores que reflejen de una forma más efectiva los niveles de colaboración (Castro et al., 2008). Sin duda, hace falta trabajo de investigación para clarificar qué y cómo pueden utilizarse otros indicadores. ${ }^{21}$

La problemática previamente enunciada plantea verdaderos desafíos a los investigadores que se desenvuelven en este campo del conocimiento, y también a los hacedores de políticas públicas. No obstante, estos problemas enunciados no son exhaustivos, por lo que podría haber otros que requieran de nuevas investigaciones.

A pesar de que pueden encontrarse problemas en la colaboración empresa-universidad, ésta también contempla varias oportunidades que pueden aprove-

\footnotetext{
${ }^{21}$ El trabajo de Cassiman et al. (2007) pretende ir más allá de los usos convencionales que se les dan a las patentes y a los artículos, pero no se desprende de tales indicadores.
} 
charse para alcanzar mayores niveles de bienestar. Veamos cuáles son algunas de las oportunidades más nítidas.

En lo que respecta a la propiedad intelectual, la colaboración debe seguir alentándose por medio del diseño de esquemas que mitiguen o eliminen los riesgos de comportamiento oportunista de los agentes. En efecto, se requieren reglas del juego muy claras y que tengan dos objetivos muy precisos, a saber: es necesario el diseño de un contrato que a la vez asegure gobernabilidad ex ante y ex post del proyecto de investigación; de hecho, según Williamson (1996), el contrato tiene la finalidad de reducir el comportamiento oportunista de los agentes y, de la misma manera, el contrato debe ser flexible en concordancia con las propiedades de la investigación. En consecuencia ¿cómo hacer para lograr una combinación de rigidez y flexibilidad que a la vez permita un manejo adecuado del conocimiento tácito y del codificado; es decir, pasar de las salvaguardas del contrato formal a los resultados o eventos imprevistos y, sin embargo, asegurar la viabilidad de la colaboración?

La teoría evolutiva, eliminando la hipótesis del comportamiento oportunista, logra resolver el problema del riesgo moral mediante el supuesto de la confianza entre los agentes, ya que sostiene que la cooperación no procede sin el conocimiento previo de los agentes que van a colaborar (García et al., 2004); ello implica que en la colaboración toma relevancia el pasado o la historia. Así pues, la cooperación puede darse con base en la reputación, tanto de las empresas como de las universidades. Si algún agente faltara a los acuerdos implícitos, a posterio$r i$ el mismo contexto económico lo sancionará (pues en la colaboración hay aprendizaje). ${ }^{22}$ Por supuesto, esta situación plantea que es necesaria más investigación en la colaboración empresa-universidad.

Otra de las oportunidades para llevar a cabo investigación adicional es la posibilidad de lograr un mayor "emprendizaje" como fruto de la colaboración, en el que los agentes universitarios asimilen las implicaciones cognitivas empresariales, teniendo como objetivo central la generación de empleos ligados a los avances científicos y tecnológicos y, por tanto, a las habilidades y capacidades suficientes para elevar los salarios, por ejemplo, impulsando la creación de parques científicos y tecnológicos. Desde luego, determinar la probabilidad de que surjan empresas de alta tecnología una vez concluidos los proyectos de investigación, requiere de mayores esfuerzos investigativos.

\footnotetext{
${ }^{22}$ Aunque la bibliografía sobre la teoría evolutiva es extensa, si algún lector desea profundizar sobre esto se sugiere revisar los trabajos de García et al. (2004) y de Taboada (2004), en los cuales se hace una revisión exhaustiva de cada una de las teorías mencionadas.
} 
Desde otro ámbito, el desarrollo de nuevas tecnologías, teniendo como soporte a la universidad, puede ser de gran utilidad para los agentes que participan directamente en ellas y para la sociedad en general, debido a que una parte importante del conocimiento y los avances tecnológicos que se van generando están en función de las necesidades y los problemas de los consumidores, las organizaciones, las regiones y los países. Ahora mismo el problema del cambio climático ha motivado grandes proyectos de investigación colaborativa. Incluso, esas nuevas tecnologías pueden dar origen a nuevos mercados. Así pues, siguiendo con el ejemplo, la preocupación del calentamiento global ha generado la integración de mercados alrededor de los productos y procesos ecológicos. Entonces, está claro que detrás de los esfuerzos de investigación colaborativa (empresauniversidad) subyace la intención de alcanzar mayores niveles de bienestar.

Adicionalmente, el riesgo de mayor concentración en el mercado puede mitigarse con la creación de nuevas pequeñas empresas de alta tecnología, por un lado, y, por el otro, impulsando la transferencia de tecnología hacia empresas del mismo tamaño pero que ya se encuentran en el mercado; es decir, basta con la aplicación de medidas selectivas para evitar beneficiar más a las grandes empresas. Además, en cuanto a las nuevas pequeñas empresas de alta tecnología, para las cuales es, probablemente, difícil encontrar mercados para sus nuevos productos y procesos, el problema se resuelve considerando un tercer agente (gobierno), que al colaborar con estas empresas y con las universidades haga que todos puedan desarrollar mercados complementarios; por ejemplo, que a partir de las compras gubernamentales también se apliquen medidas selectivas para beneficiar a las nuevas pequeñas empresas, sobre todo en las primeras etapas de su existencia.

Por último, dado que nos encontramos inmersos en un entorno económico y social donde el conocimiento científico y tecnológico es decisivo para desarrollar nuevas capacidades y habilidades para, de esa manera, aspirar a mayores niveles de bienestar social y empresas más competitivas, conviene seguir impulsando la colaboración entre empresas y universidades.

\section{CONCLUSIONES}

Si las empresas aspiran a ser más competitivas en un contexto de "economía del conocimiento", deberán hacer grandes esfuerzos para involucrarse directa o indirectamente en tal actividad; es decir, deberán actuar para lograr dos metas: por un lado, requieren financiar más investigación y desarrollo internos; por el otro, una vez alcanzadas las capacidades y habilidades necesarias para este contexto, 
deberán estrechar sus vínculos con los centros del conocimiento (universidades). En efecto, empresas de los sectores de alta tecnología se han vinculado fuertemente con las universidades a fin de complementar sus activos tangibles e intangibles, disminuir los costos de financiamiento de los proyectos y adquirir mayores habilidades y capacidades en la producción y gestión del conocimiento científico y tecnológico.

Quizá lo que sigue puede ser muy intuitivo o todavía especulativo, pero en el trabajo puede asentarse que la economía y la sociedad del conocimiento deben propiciar el paso de las protoempresas y las protouniversidades a las organizaciones económicas del conocimiento, en las que la gestión del mismo deberá estar en el centro de las decisiones sobre la producción y el intercambio del conocimiento como bien económico.

En principio, la colaboración universidad-empresa puede explicarse a partir de la teoría de las externalidades o de los spillovers, debido a que en una economía de mercados competitivos las empresas no estarán dispuestas a invertir en ciencia básica porque genera externalidades positivas o derrama del conocimiento; por tanto, tales inversiones no serían rentables por las mismas características que implica ese conocimiento y se recurriría a la colaboración con las universidades. Pero si eso sucede, ¿cómo explicar la inversión que muchas empresas llevan a cabo en ciencia y tecnología? La respuesta viene dada por los instrumentos de la nueva economía institucional en la que se asume que para acceder al conocimiento se requieren capacidades y habilidades previas. De manera sencilla puede establecerse que la ausencia de inversiones importantes en la generación de conocimiento (científico y tecnológico) interno es al mismo tiempo la imposibilidad o la gran dificultad para acceder al conocimiento externo generado en las universidades.

Por otro lado, las universidades, empujadas por un contexto socioeconómico en el que los subsidios públicos disminuyen, y en el que se exige un papel más activo en el crecimiento y desarrollo económicos, comienzan a tomar como función adicional la comercialización abierta del conocimiento, grosso modo mediante el registro de patentes y el licenciamiento de la propiedad intelectual a las firmas, funciones todas originalmente muy de empresa. En este sentido, empresa y universidad podrían considerarse protouniversidad y protoempresa, respectivamente.

Asimismo, dado que la coordinación económica se lleva a cabo por mecanismos que van desde el precio hasta la jerarquía, la cooperación universidadempresa estaría situada en un punto de ese continuo. Este tipo de coordinación es 
conocida como híbrida; en ella se combinan ventajas económicas que en ocasiones son mayores a las que se presentan en el mercado y en otras ocasiones mayores a las obtenidas por medio de la empresa convencional. En tales condiciones, la colaboración entre estas organizaciones es la mejor opción para adquirir capacidades y habilidades necesarias en un entorno de competencia cada vez más complejo.

Finalmente, la colaboración entre estos dos agentes parece ser un fenómeno creciente e irreversible, y aunque algunas investigaciones arrojen evidencias contradictorias, en el largo plazo se puede sostener este juicio. En consecuencia, existen temas y líneas de investigación que representan grandes desafíos (problemas) y a la vez oportunidades de investigación futura, debido a que está pendiente la respuesta consistente a varias preguntas encontradas en la bibliografía sobre este tema. Entre las preocupaciones de mayor relevancia se encuentra la de que los vínculos provoquen una mayor concentración del mercado y propicien estructuras industriales monopólicas u oligopólicas; para ese problema potencial se propone la selectividad en la colaboración con las empresas. 


\section{REFERENCIAS BIBLIOGRÁFICAS}

Agrawal, Ajay (2001), "University to industry knowledge transfer: literature review and unanswered questions", International Journal of Management Review, Vol. 3, núm. 4, pp. 285-302.

Arellano, Antonio (1996), "La capacidad de innovación tecnológica en la Universidad Autónoma del Estado de México”, Convergencia, año 4, núms. 12-13, Toluca, México, UAEM.

Arora, Ashish, y Alfonso Gambardella (1990), “Complementary and external linkages: the strategies of large firms in biotechnology", The Journal of Industrial Economics, Vol. XXXVIII, pp. 361-379.

Arrow, Keneth (1962), "El bienestar económico y la asignación de recursos para la invención”, en Nathan Rosenberg (ed. 1979), Economía del cambio tecnológico, FCE, México.

Audretsch, David (2005), "The knowledge spillover theory of entrepreneurship and economic growth", Research on Technological Innovation, Management and Policy, Vol. 9, pp. 37-54.

Baldini, Nicola (2008), "Negative effects of university patenting: Myths and grounded evidence", en Scientometrics, Vol. 75, núm. 2, pp. 289-311.

Bercovitz, Janet, y Maryann P. Feldman (2007), "Fishing upstream: Firm innovation strategy and university research alliances”, Research Policy, Vol. 36, mayo, pp. 930948.

Blumenthal, David, Michael Gluck, Karen Louis y David Wise (1986), “Industrial Support of University Research in Biotechnology", Science, Vol. 231, núm. 4735, pp. 242-246.

Breschi, Stefano, F. Lissoni, y F. Montobbio (2005), "Open Science and University Patenting: A Bibliometric Aproach", Van Pottelsberghe de la Potterie y De Meyer A. (eds.), Economic and Management Perspectives on Intellectual Property Rights, Palgrave McMillan.

Burrone, Esteban, y Guriqbal Singh (2004), Intellectual Property (IP) Rights and Innovation in Small and Medium-Sized Enterprises, WIPO, Ginebra, p. 23.

Callon, Michel (1999), "Actor-network theory-the market test", The Editorial Board of the Sociological Review, Blackwell Publishers, EUA.

Casas, Rosalba (coord.) (2001), La formación de redes de conocimiento. Una perspectiva regional desde México, Anthropos, UNAM-Instituto de Investigaciones Sociales, México. 
Cassiman, Bruno, Patrick Glenisson, y Bart van Looy (2007), "Measuring industry-science links through inventor-author relations: A profiling methodology", Scientometrics, Vol. 70, núm. 2, pp. 379-391.

Castro, Elena, Jordi Molas, e Ignacio Fernández (2008), "Knowledge transfer in the human and social sciences: The importance of informal relationships and its organizational consequences", Policies for Research and Innovation in Moving Towards the European Research Area, Europe-Latin America Conference on Science and Innovation Policy, ciudad de México, septiembre 24-26.

Cimoli, Mario (2007), Sources of learning paths and technological capabilities. An introductory roadmap on development process, ponencia preparada para la reunión del Club Brisbane, Pollenza, Italia, 1-3 de junio.

Cockburn, Iain, y Rebecca Henderson (1998), "Absortive Capacity, Coauthoring Behavior, and the Organization of Research in Drug Discovery", The Journal of Industrial Economics, Vol. 46, núm. 2, pp. 157-182.

Cohen, Wesley, y Daniel Levinthal (1990), “Absortive Capacity: A New Perspective on Learning and Innovation", Administrative Science Quarterly, Vol. 35, núm. 1, pp. 128-152.

Ducor, Philippe (2000), "Coauthorship and Coinventorship", Science, New Series, Vol. 289, núm. 5481, pp. 873-875.

Dutrénit, Gabriela (1996), "La vinculación universidad-empresa en un macroproyecto de polímeros", Comercio Exterior, Vol. 46, núm. 10, pp. 808-816.

Etzkowitz, Henry, Andrew Webster, Christiane Gebhardt, y Branca R. Cantisano (2000), "The future of the university and the university of the future: evolution of ivory tower to entrepreneurial paradigm", Research Policy, Vol. 29, pp. 313-330.

(2002), "The Triple Helix of University-Industry-Government, Implications for Policy and Evaluation", Working Paper 2002.11, Science Policy Institute. (2003), "Research groups as 'quasi-firms': the invention of the entrepreneurial university", Research Policy, Vol. 32, pp. 109-121.

Foray, Dominique (1991), "The secrets of industry are in the air: Industrial cooperation and the organizational dynamics of the innovative firm", en Research Policy, Vol. 20, pp. 393-405.

García, Alejandro, Arturo Lara, y Eunice Taboada (2004), "La coordinación 'híbrida' desde las perspectivas de Williamson y de Nooteboom”, en Análisis Económico, Vol. XIX, núm. 040, UAM-Azcapotzalco, México, pp. 101-117.

Griliches, Zvi (1958), “Costos de investigación y rendimientos sociales: el maíz híbrido e innovaciones relacionadas", en Rosenberg, Nathan (ed.1979), Economía del cambio tecnológico, FCE, México. 
Jalife-Rahme, Alfredo (2007), Hacia la desglobalización, 2ª edición, Jorale Editores y Orfila, México.

Katz, J. Sylvan, y Ben R. Martin (1997), “What is research collaboration?”, Research Policy, Vol. 26, pp. 1-18.

Kay, Neil (1988), “The R+D function: corporate strategy and structure”, en Giovani Dosi, et al. (eds.), Technical Change and Economic Theory, Pinter Publishers, Londres y Nueva York.

Link, Albert, John T. Scott, y Donald S. Siegel (2003), “The economics of intellectual property at universities: on overview of the special issue", International Journal of Industrial Organization, núm. 21, pp. 1217-1225.

Lissoni, Francesco, y Fabio Montobbio (2008), "Inventorship and Authorship in PatentPublication Pairs: an Enquiry into the Economics of Scientific Credit", Working Paper, núm. 224, Centro di Ricerca sui Processi di Innovazione e Internazionalizzazione, Università Commerciale Luigi Bucconi, Milán.

Lucas, Mikkel (2007), "Partner Selection Criteria in Strategic Alliances: When to Ally with Weak Partners", Working Paper, núm. 05-07, Danish Research Unit for Industrial Dynamics, Copenhagen Business School, Copenhague.

Luna, Matilde (coord.) (2003), Itinerarios del conocimiento: formas, dinámicas y contenido. Un enfoque de redes, UNAM-IIS, Anthropos, México.

Lund, Anker (2004), "Interaction between Firms and Knowledge Institutions", Research on Technological Innovation and Management Policy, Vol. 8, pp. 257-283.

Lundvall, Bengt-Ake (2004), "The Economics of Knowledge and Learning", Research on Technological Innovation and Management Policy, Vol. 8, pp. 21-42.

Marshall, Alfred (1920), Principles of Economics, An introductory volume, 9a. edición, 1961, Macmillan and Co. Limited, Londres.

Merritt, Humberto (2007), "La vinculación industria-centros tecnológicos de investigación y desarrollo: el caso de los centros CONACYT de México", Análisis Económico, Vol. XXII, núm. 49, UAM-Azcapotzalco, pp. 149-168, México.

Meyer-Krahmer, Frieder, y Ulrico Schmoch (1998), "Science-based technologies: university-industry interactions in four fields", Research Policy, Vol. 27, pp. 835-851.

Nelson, Richard (1959), "La economía sencilla de la investigación científica básica”, en Nathan Rosenberg, (ed.1979), Economía del cambio tecnológico, FCE, México.

_ (2008), “Institutions, 'Social Technologies', and Economic Progress”, Working Papers Series, núm. 2007-03, GLOBELICs Organization.

Pavitt, Keith (1984), "Sectoral patterns of technical change: Towards a taxonomy and a theory", Research Policy, Vol. 13, pp. 343-373. 
Rahm, Dianne (1994), “Academic Perceptions of University-Firm Technology Transfer”, Policy Studies Journal, Vol. 22, núm. 2, pp. 267-278.

Romer, Paul (1986), "Increasing returns and long-run growth", Journal of Political Economy, Vol. 94, pp. 1002-1037.

Shane, Scott, y Toby Stuart (2002), "Organizational Endowments and the Performance of University Start-Ups", Management Science, Vol. 48, núm. 1, pp. 154-170.

Taboada, Eunice (2004), ¿Qué hay detrás de la decisión de cooperar tecnológicamente? Propuesta teórica integradora para explicar la cooperación tecnológica interempresa, tesis del doctorado en Ciencias Económicas, UAM, México.

Teece, David, Gary Pisano, y Amy Shuen (1997), "Dynamic Capabilities and Strategic Management”, Strategic Management Journal, Vol. 18, núm. 7, pp. 509-533.

Thompson, Peter, y Melanie Fox-Kean (2005), "Patent citations and geography of knowledge spillovers: a reassessment”, The American Economic Review, Vol. 9, pp. 450-460.

Welsh, Rick, Leland Glenna, William Lacy, y Dina Biscotti (2008), “Close enough but not too far: Assessing the effects of university-industry research relationships and the rise of academic capitalism", Research Policy, Vol. 37, pp. 1854-1864.

Williamson, Oliver (1975), Mercados y jerarquías: su análisis y sus implicaciones antitrust, FCE, México, 1991.

(1985), Las instituciones económicas del capitalismo, FCE, México, 1989.

(1996), "La lógica de la organización económica", en Oliver Williamson, y Sidney Winter (comp.), La naturaleza de la empresa. Orígenes, evolución y desarrollo, FCE, México.

Winter, Sidney (1996), “Coase, la competencia y la corporación”, en Oliver Williamson, y Sidney Winter (comp.), La naturaleza de la empresa. Orígenes, evolución y desarrollo, FCE, México. 